\title{
PENERAPAN STANDART ISSU TERKINI DALAM KESELAMATAN PASIEN OLEH PERAWAT DI RUMAH SAKIT
}

\author{
Nadia Febriani Br. Barus
}

Nadiafebriani001@gmail.com

Latar belakang : Keselamatan pasien menjadi isu prioritas dalam perawatan kesehatan dan Keselamatan pasien merupakan hak pasien. Pasien berhak memperoleh keamanan dan keselamatan dirinya selama dalam perawatan di rumah sakit. pelayanan kesehatan harus mendahulukan keselamatan nyawa pasien. Keselamatan pasien telah menjadi prioritas untuk layanan kesehatan diseluruh dunia Keselamatan pasien merupakan komponen penting dari mutu layanan kesehatan. membuat kebijakan atau prosedur yang dikembangkan yang mendukung secara terus menerus pengurangan infeksi terkait dengan perawatan kesehatan. Kebijakan tersebut terdiri dari mengidentifikasi pasien dengan benar, peningkatan komunikasi yang efektif, peningkatan keamanan obat-obatan yang perlu diwaspadai, memastikan lokasi pembedahan yang benar, prosedur yang benar, pembedahan pada pasien yang benar, pengurangan resiko infeksi akibat perawatan kesehatan, dan mengurangi risiko pada pasien akibat jatuh. keselamatan pasien menjadi isu terkini karena makin meningkatnya kejadian tidak diharapkan (KTD) atau adverse event. Insiden keselamatan pasien di rumah sakit akan memberikan dampak yang merugikan bagi pihak rumah sakit, staf dan pasien pada khususnya karena sebagai penerima pelayanan. Dampak yang ditimbulkan adalah menurunnya tingkat kepercayaan masyarakat terhadap pelayanan kesehatan yang terjadi akibat rendahnya kualitas dan mutu asuhan yang diberikan. Tujuan dari penelitian ini adalah untuk mengidentifikasi pelaksanaan enam sasaran keselamatan pasien oleh perawat dalam mencegah adverse event di Rumah Sakit Keselamatan menjadi isu global dan terangkum dalam lima isu penting yang terkait di rumah sakit yaitu keselamatan pasien, keselamatan pekerja atau petugas kesehatan, keselamatan bangunan dan peralatan di rumah sakit yang bisa berdampak terhadap keselamatan pasien dan petugas. Keselamatan lingkungan yang berdampak terhadap pencemaran lingkungan dan keselamatan bisnis rumah sakit yang terkait dengan kelangsungan hidup rumah sakit. Keselamatan pasien merupakan prioritas utama untuk dilaksanakan terkait dengan isu mutu dan citra perumahsakitan. Gerakan (Patient Safety) keselamatan pasien telah menjadi spirit dalam pelayanan rumah sakit seluruh dunia tidak hanya rumah sakit di negara maju yang menerapkan keselamatan pasien untuk menjamin mutu pelayanan, tetapi juga rumah sakit di negara berkembang seperti di Indonesia (Depkes, 2006). Peraturan ini menjadi tonggak utama operasionalisasi keselamatan pasien di rumah sakit seluruh Indonesia. Banyak rumah sakit di Indonesia yang telah berupaya membangun dan mengembangkan keselamatan 
pasien, namun upaya tersebut dilaksanakan berdasarkan pemahaman manajemen terhadap keselamatan pasien.

Metode: Kualitas perawatan telah menjadi fokus yang sangat penting di bidang perawatan kesehatan primer untuk beberapa waktu dan pekerjaan ini terkait dengan perbaikan hasil yang cukup besar pada pasien. Dalam bidang ini, pemeriksaan keselamatan pasien baru saja muncul sebagai fokus yang berbeda selama dekade terakhir. Ada kesadaran yang meningkat bahwa risiko yang teridentifikasi di sektor perawatan akut terwujud dalam berbagai cara dalam perawatan kesehatan primer. Solusi yang dikembangkan dalam perawatan akut belum tentu berlaku di sini. Praktisi perawatan kesehatan primer dapat belajar dari sektor perawatan akut, namun juga perlu memeriksa secara seksama proses dan sistem mereka sendiri untuk mengidentifikasi risiko pasien tertentu dan solusi yang mungkin terjadi. Keselamatan pasien dan kualitas pasien adalah jantung dari penyampaian layanan kesehatan. Untuk setiap pasien, yang merawat, anggota keluarga dan profesional kesehatan, keselamatan sangat penting untuk penegakan diagnosa, tindakan kesehatan dan perawatan. Dokter, perawat dan semua orang yang bekerja di sistem kesehatan berkomitmen untuk merawat, membantu, menghibur dan merawat pasien dan memiliki keunggulan dalam penyediaan layanan kesehatan untuk semua orang yang membutuhkannya.

Hasil: Rumah sakit harus memiliki sistem dan mekanisme mendidik pasien dan keluarganya tentang kewajiban dan tanggung jawab pasien dalam asuhan pasien. Hal ini sesuai dengan yang diungkapkan oleh informan kunci pada saat wawancara sebagai berikut: "pasien mendapatkan informasi yang benar, jelas, jujur dan lengkap tanpa mengurangi informasi yang diberikan karena menyangkut tentang kesehatan pasien". Perawat yang bekerja di rumah sakit bekerja penuh dengan mendapat gaji,dalam ilmu hukum dikenal doktrin Vicarius Liability atau respondeat superior atau hubungan majikan dengan buruh.Dalam hal ini rumah sakit disebut majikan. Disamping itu hubungan yang timbul dari tenaga perawatan dan pihak rumah sakit dikuasai juga oleh hukum perburuhan. Dalam praktek juga terdapat tenaga kesehatantertentu yang tidak mempunyai hubungan perburuhan pada rumah sakit, intinya seorang perawat dengan sifat profesionalismenya bertanggungjawab atas kerugian pasien yang disebabkan kelalaiannya, dengan alas an rumah sakit mempergunakan tenaga perawat kontrak lepas. Selanjutnya apabila di lihat dari hubungan hukum yang timbul antara pasien dan rumah sakit dapat dibedakan pada 2 macam perjanjian, yaitu : 1. Perjanjian perawatan dimana terdapat kesepakatan antara rumah sakit dan pasien bahwa pihak rumah sakit menyediakan kamar perawatan dan dimana tenaga perawat melakukan tindakan perawatan. 2. Perjanjian pelayanan medis di mana terdapat kesepakatan antara rumah sakit dan pasien bahwa tenaga medis pada rumah sakit akan berupaya secara maksimal untuk menyembuhkan pasien melalui 
tindakan medis (inspannings verbintenis). Untuk menilai sahnya perjanjian tersebut dapat diterapkan Pasal 1320 KUH Perdata,sedangkan untuk pelaksanaan perjanjian itu sendiri harusdilaksanakan dengan itikad baik sesuai denga ketentuan pasal 1338 dan 1339 KUHPerdata. Bertitik tolak dari hal diatas maka hubungan pasien dan tenaga perawat di rumah sakit dapat berupa hubungan hukum pasien dengan dokter, juga hubungan pasien dengan perawat yang

berupa kontrak, dimana tenaga kesehatan harus berupaya memberikan pelayanan sesuai dengan kemampuan dan perangkat ilmu yang dimiliki. Kontrak ini dapat inspanings verbintenis maupun resultaatsverbintenis.Selanjutnya hubungan hukum antara dokter dengan perawat dapat merupakan hubungan rujukan atau delegasi. Pada hubungan rujukan tenaga lain tersebut melakukan tindakan sesuai dengan keputusannya sendiri sedangkan delegasi tenaga kesehatan lain tidak dapat mengambil kebijaksanaan sendiri tapi melakukan tindakan sesuai dengan delegasi yang diberian oleh dokternya, Di suatu rumah sakit para dokter tidak bisa bekerja tanpa bantuan perawat. Sebaliknya perawat bekerja harus berdasarkan instruksi dokter, perawat tidak berwenang untuk menindak secara mandiri, kecuali dalam bidang tertetu yang sifatnya umum dan termasuk asuhan perawat (nursing care). Namun kenyataannya sehari-hari perawat melakukan tindakan yang sebenarnya termasuktugas dokter.Sejak dahulu kala, ada batas yang tidak jelas antara tindakan yang termasuk bidang medis yang harus dilakukan oleh profesi kedokteran dan tindakan yang termasuk wewenang profesi perawat.Terdapat suatu wilayah bidang yang dilakukan oleh para perawat yang sebenarnya termasuk bidang medis. Dilihat dari segi perawatan, tampak ada bidang yang saling tumpang tindih. Dasar hukum pendelegasian ini diberikan dalam suatu arrest hoge raad tanggal 4 November1952 dimana dikatakan bahwa orang yang belum pernah menjadi dokter (dimaksudkan semi arts) dapat melakukan tindakan kedokteran di bawah pengawasan. Ketentuan ini diberlakukan juga pada perawat ini disebut juga perpanjangan lengan dokter atau teori verlengde arm van de arts.

Pembahasan: patient Safety atau keselamatan pasien adalah suatu system yang membuat asuhan pasien di rumah sakit menjadi lebih aman. Sistem ini mencegah terjadinya cedera yang disebabkan oleh kesalahan akibat melaksanakan suatu tindakan atau tidak mengambil tindakan yang seharusnya diambil. Fasilitas pelayanan kesehatan menjamin keselamatan pasien dalam kesinambungan pelayanan dan menjamin koordinasi antar tenaga dan antar unit pelayanan. Hal tersebut didukung dengan hasil wawancara dengan informan kunci sebagai berikut: "Koordinasi pelayanan di mulai dari antar bidang pelayanan, bidang penunjang, bidang informasi, dan termasuk tata usaha juga. Dalam bidang pelayanan dari mulai pasien masuk, dilakukan pemeriksaan, misal membutuhkan cek lab, sampai dengan pasien keluar dari rumah sakit ini ada koordinasinya yang melibatkan dokter dan tenaga kesehatan lainnya"(Informan A). 
Hal serupa juga diungkapkan oleh informan lain, sebagai berikut: "Ya kita kordinasikan supaya pelayanannya bisa maksimal dan tepat" (Informan C). Selain koordinasi pelayanan yang menyeluruh untuk kesinambungan pelayanan, rumah sakit harus memiliki koordinasi pelayanan yang disesuaikan dengan kebutuhan pasien dan kelayakan sumber daya secara berkesinambungan sehingga pada seluruh tahap pelayanan transisi antar unit pelayanan dapat berjalan dengan baik dan lancar. Sebagaimana yang diungkapkan oleh informan kunci dalam proses wawancara sebagai berikut: "Terdapat koordinasi yang disesuaikan dengan kebutuhan pasien" (Informan A). Hal ini juga didukung dengan jawaban dari informan lain saat melakukan wawancara, sebagai berikut: "Ada koordinasinya harus jelas sesuai dengan kebutuhan pasien. Koordinasinya itu petugas akan memberikan tindakan dari hasil pencatatan terkait pemeriksaan selanjutnya yang akan dilaksanakan..."(Informan D). Untuk menjamin keselamatan pasien dalam kesinambungan pelayanan, di rumah sakit harus terdapat komunikasi dan transfer informasi antar profesi kesehatan sehingga dapat tercapainya proses koordinasi tanpa hambatan, aman, dan efektif. Hal ini didukung dengan hasil wawancara dengan informan kunci sebagai berikut: "Terdapat transfer informasi antar profresi kesehatan karena kalau pelayanan hanya dilakukan dokter saja maka pelayanan tidak akan berjalan dengan lancar" (Informan A). Hal serupa juga diungkapkan oleh informan lain, sebagai berikut: "Tentu ada transfer informasi antar petugas kesehatan dengan cara berdiskusi" (Informan B). Berdasarkan hasil penelitian, Rumah Sakit Umum Daerah Provinsi Nusa Tenggara Barat telah menerapkan standar keselamatan pasien dan kesinambungan pelayanan, dapat dilihat dari koordinasi yang dilakukan oleh petugas rumah sakit. Koordinasi merupakan salah satu hal yang wajib terdapat di dalam kesinambungan sebuah pelayanan. Pelayanan yang menyeluruh bertujuan agar seluruh proses pengobatan pasien tidak ada yang terlewati. Tidak adanya koordinasi yang dapat menyebabkan kegagalan medis pada pasien yang seharusnya dilakukan pelayanan yang berkesinambungan sampai pada akhir pengobatan. Pelayanan akan berjalan lancar dan sesuai tujuan ketika terdapat koordinasi antar pegawai di setiap unit. Hal ini sesuai dengan penelitian yang dilakukan oleh Hakim dan Pudjirahardjo (2014) yang mengatakan bahwa proses perencanaan program keselamatan pasien menghasilkan berbagai macam kegiatan dan aktivitas yang spesifik yang tersebar di dalam berbagai unit kerja. Setiap unit kerja memiliki karakteristik kegiatan maupun aktivitas terkait tugas program keselamatan pasien yang berbeda dengan unit kerja lain. Perbedaan karakteristik kegiatan maupun aktivitas diperlukan sebuah mekanisme koordinasi yang dilakukan oleh unit kerja untuk menghubungkan tugas. Ketersediaan sumber daya di fasilitas kesehatan dibutuhkan untuk memberikan pelayanan yang prima sehingga dapat memberikan kepuasan kepada pasien. Adanya komunikasi antar profesi kesehatan untuk menjaga kesinambungan pelayanan dan mencegah pengulangan pelayanan yang tidak efesian selama pasien di rawat di rumah sakit. Peran kepemimpinan dalam meningkatkan keselamatan pasien Standar tentang peran kepemimpinan dalam meningkatkan keselamatan pasien bahwa di Rumah Sakit Umum Daerah Provinsi Nusa tenggara Barat sudah 
melakukan dengan baik sesuai dengan Peraturan Menteri kesehatan Nomor 11 Tahun 2017. Dimulai dari rumah sakit telah melaksanakan standarnya yang meliputi adanya tim antar disiplin untuk mengelola program keselamatan pasien yaitu tim komite keselamatan pasien di rumah sakit. Hal ini dukung dengan hasil wawancara dengan informan kunci sebagai berikut : "Memang sudah ada timnya ini, jadi di kan nanti di dalam apa e komite peningkatan mutu dan keselamatan pasien ada timnya untuk peningkatan mutu ada juga sub komite keselamatan pasien, jadi untuk yang di tim itu bukan hanya semua dokter saja, dari perawat ada. Kalau kordinasi kerjanya ya kita akan tetap berkomunikasi, ya artinya kita tidak bisa mau bekerja sendiri, nanti mana kala terjadi insiden kita akan juga memanggil timnya, kan nanti disitu ada timnya juga untuk apa, apakah untuk tim manajemen resikonya itu disitu gitu loh, jadi apakah insiden itu nanti masuk sentinel, masuk KPC, masuk KTD itu berdasarkan dari investigasinya dari gradingnya itu". Komunikasi terhadap berbagai informasi mengenai perkembangan pasien antar profesi kesehatan di rumah sakit merupakan komponen yang fundamental dalam perawatan pasien (Riesenberg,2010). Transfer informasi pada saat pergantian shift yang disebut dengan handover bertujuan untuk menyampaikan informasi dari setiap pergantian shift serta memastikan efektifitas dan keamanan dalam perawatan pasien. Informasi terkait dengan keadaan klinis pasien, kebutuhan pasien, keadaan personal pasien, sampai pada faktor sosial pasien. Perawat harus datang minimal 15 menit lebih awal untuk mengikuti handover sehingga proses handover dapat berjalan lancer. Semua faktor yang dapat menentukan atau membentuk perilaku manusia disebut determinan perilaku. Determinan perilaku manusia terdiri dari faktor internal dan factor eksternal. Faktor internal yaitu karakteristik dari individu yang bersangkutan yang bersifat bawaan sedangkan faktor eksternal yaitu faktor yang berasal dari luar diri seseorang (Notoatmodjo, 2010). Berdasarkan hasil penelitian dapat disimpulkan bahwa sebagian besar perawat pelaksana memiliki perilaku yang baik dalam penerapan manajemen Kesehatan dan Keselamatan Kerja (K3) baik ditinjau dari faktor internal (52.5\%) maupun factor eksternal (58.8\%). Berdasarkan asumsi peneliti ada berbagai faktor yang dapat mempengaruhi perilaku perawat ditinjau dari faktor internal berada pada kategori baik, diantaranya persepsi. Persepsi merupakan suatu proses pencarian informasi yang dilakukan oleh perawat sebelum melakukan suatu tindakan. Persepsi perawat tentang K3 menunjukkan bagaimana perawat mampu mencari tahu tentang pentingnya K3 baik melalui brosur, leaflet, SOP yang disediakan di ruangan maupun media informasi lainnya. Perawat juga dituntut untuk faham bagaimana cara pencegahan kecelakaan serta penanganan yang dapat dilakukan apabila kecelakaan terjadi. Pemahaman tersebut akan menimbulkan persepsi yang baik dalam diri perawat tentang K3 sehingga hal ini akan meningkatkan perilakunya dalam menjaga keselamatan. pengetahuan dan sikap perawat dalam menjaga kesehatan dan keselamatan selama bekerja, diantaranya dengan memberikan promosi kesehatan dan pelatihan tentang K3 sehingga hal ini diharapkan mampu merubah perilaku perawat menjadi lebih baik. Selain faktor internal, faktor eksternal juga sangat mempengaruhi perilaku perawat dalam penerapan manajemen K3 di rumah sakit. 
Peneliti berasumsi bahwa ada banyak faktor yang dapat menentukan perubahan perilaku perawat dari segi faktor eksternal, diantaranya pengalaman. Pengalaman perawat dapat dilihat dari berbagai aspek. Terkait dengan program pendidikan, pelatihan dan orientasi petugas kesehatan selalu diberikan apalagi untuk staf baru kegiatan pelatihan selalu diberikan tidak hanya kegiatan pelatihan di dalam rumah sakit tetapi diluar rumah sakit juga dilakukan kegiatan pelatihan sebagai tambahan untuk ilmu yang bisa diterapkan di rumah sakit TUJUH LANGKAH :Standar keselamatan pasien menurut Peraturan Menteri Kesehatan Nomor 1691/Menkes/Per/VIII/2011 tentang Keselamatan Pasien Rumah Sakit, Pasal 7 ayat (2) meliputi:Hak pasien; Mendidik pasien dan keluarga; Keselamatan pasien dalam kesinambungan pelayanan; Penggunaan metode peningkatan kinerja untuk melakukan evaluasi dan program peningkatan keselamatan pasien; Peran kepemimpinan dalam meningkatkan keselamatan pasien; Mendidik staf tentang keselamatan pasien;dan Komunikasi merupakan kunci bagi staf untuk mencapai keselamatan pasien. Selanjutnya Pasal 8 Peraturan Menteri Kesehatan tersebut diatas mewajibkan setiap Rumah Sakit untuk mengupayakan pemenuhan Sasaran Keselamatan Pasien yang meliputi tercapainya 6 (enam) hal sebagai berikut: Ketepatan identifikasi pasien; Peningkatan komunikasi yang efektif; Peningkatan keamanan obat yang perlu diwaspadai; Kepastian tepat-lokasi, tepat-prosedur, tepat-pasien operasi; Pengurangan risiko infeksi terkait pelayanan kesehatan;dan Pengurangan risiko pasien jatuh. Dalam rangka menerapkan Standar Keselamatan Pasien, menurut Pasal 9 Peraturan Menteri Kesehatan tersebut diatas, Rumah Sakit melaksanakan Tujuh Langkah Menuju Keselamatan Pasien Rumah Sakit yang terdiri dari: Membangun kesadaran akan nilai keselamatan pasien; Memimpin dan mendukung staf; Mengintegrasikan aktivitas pengelolaan risiko; Mengembangkan sistem pelaporan; Melibatkan dan berkomunikasi dengan pasien; Belajar dan berbagi pengalaman tentang keselamatan pasien;dan Mencegah cedera melalui implementasi sistem keselamatan pasien. Melalui penerapan tujuh langkah tersebut diharapkan hak pasien yang dijamin dalam Pasal 32 Undang-Undang Nomor 44 tahun 2009 tentang Rumah Sakit, terpenuhi. Hak tersebut antara lain untuk memperoleh layanan kesehatan yang bermutu sesuai dengan standar profesi dan standar prosedural operasional serta layanan yang efektif dan efisien sehingga pasien terhindar dari kerugian fisik dan materi. Asosiasi perumahsakitan dan organisasi profesi kesehatan menurut Pasal 10 Peraturan Menteri Kesehatan tentang Keselamatan Pasien Rumah Sakit, wajib berperan serta dalam persiapan penyelenggaraan Program Keselamatan Pasien Rumah Sakit. Hak pasien,Standarnya adalah Pasien \& keluarganya mempunyai hak untuk mendapatkan informasi tentang rencana \& hasil pelayanan termasuk kemungkinan terjadinya KTD (Kejadian Tidak Diharapkan). Kriterianya adalah Harus ada dokter penanggung jawab pelayanan Dokter penanggung jawab pelayanan wajib membuat rencana pelayanan Dokter penanggung jawab pelayanan wajib memberikan penjelasan yang jelas dan benar kepada pasien dan keluarga tentang rencana dan hasil pelayanan, pengobatan atau prosedur untuk pasien termasuk kemungkinan terjadinya KTD, Mendidik pasien dan keluarga Standarnya 
adalah RS harus mendidik pasien \& keluarganya tentang kewajiban \& tanggung jawab pasien dalam asuhan pasien.

Penutup: Pelaksanaan enam sasaran keselamatan pasien oleh perawat di rumah sakit berada dalam kategori baik. Diharapkan Pihak rumah sakit dapat melengkapi standar prosedur operasional mengenai komunikasi efektif saat melaporkan dan menerima instruksi dari dokter, adanya tanda dan label untuk keamanan obat, dan peningkatan supervisi agar pelaksanaan teknik aseptik menjadi lebih baik. Keselamatan pasien adalah proses dalam suatu rumah sakit yang memberikan pelayanan pasien secara aman. Proses tersebut meliputi pengkajian mengenai resiko, identifikasi, manajemen resiko terhadap pasien, pelaporan dan analisis insiden, kemampuan untuk belajar dan menindaklanjuti insiden, dan menerapkan solusi untuk mengurangi serta meminimalisir timbulnya risiko. Pelayanan kesehatan yang diberikan tenaga medis kepada pasien mengacu kepada tujuh standar pelayanan pasien rumah sakit yang meliputi hak pasien, mendididik pasien dan keluarga, keselamatan pasien dan kesinambungan pelayanan, penggunaan metode- metode peningkatan kinerja untuk melakukan evaluasi dan program peningkatan keselamatan pasien, peran kepemimpinan dalam meningkatkan keselamatan pasien, mendidik staf tentang keselamatan pasien, dan komunikasi merupakan kunci bagi staf untuk mencapai keselamatan pasien.

\section{Daftar pustaka :}

1. Simamora, R. H., \& Nurmaini, C. T. S. (2019). Knowledge of Nurses about Prevention of Patient Fall Risk in Inpatient Room of Private Hospital in Medan. Indian Journal of Public Health Research \& Development, 10(10), 759-763.

2. Nanda Hani Juniarti \& Ahmad Ahid Mudayana. 2018. ENERAPAN STANDAR KESELAMATAN PASIEN DI RUMAH SAKIT UMUM DAERAH PROVINSI NUSA TENGGARA BARAT. Jurnal Kesehatan Poltekkes Ternate, VOL 11 NO 2, HAL $93-108$

3. Reno Afriza Neri, Yuniar Lestari, dan Husna Yetti.2018. ANALISIS PELAKSANAAN SASARAN KESELAMATAN PASIEN DI RAWAT INAP RUMAH SAKIT UMUM DAERAH PADANG PARIAMAN. Jurnal Kesehatan Andalas. VOL 7 NO 4 HAL 49-55

4. Rospita A.Siregar.2016. HUBUNGAN PERAWAT DAN PASIEN: IMPLEMENTASI STANDAR KESELAMATAN PASIEN. Jurnal Hukum tô-râ, Vol. 2 No. 1, HAL 295-304. 
5. Yeni Yarnita.2018. ANALISIS HUBUNGAN SIKAP PERAWAT DENGAN BUDAYA KESELAMATAN PASIEN DI RUANG RAWAT INAP RSUD ARIFIN ACHMAD PROVINSI RIAU. Jurnal Photon Vol. 8 No. 2 HAL 81-85.

6. Arfella Dara Tristantia.2018.EVALUASI SISTEM PELAPORAN INSIDEN KESELAMATAN PASIEN DI RUMAH SAKIT The Evaluation of Patient Safety Incident Reporting System at a Hospital. Jurnal Administrasi Kesehatan Indonesia Volume 6 No 2 HAL 83-94

7. Riska Nazirah \& Yuswardi.2017.PERILAKU PERAWAT DALAM PENERAPAN MANAJEMEN KESEHATAN DAN KESELAMATAN KERJA (K3) DI ACEH Nurses Behavior in The Implementation of The Occupational Health and Safety in Aceh. Idea Nursing Journal Vol. VIII No. 3 HAL 1-5

8. Hasbi Ibrahim, Dwi Santy Damayati, Munawir Amansyah \& Sunandar.2017.GAMBARAN PENERAPAN STANDAR MANAJEMEN KESELAMATAN DAN KESEHATAN KERJA RUMAH SAKIT DI RUMAH SAKIT UMUM DAERAH HAJI MAKASSAR. VOLUM AI-Sihah : Public Health Science Journal E IX, NO. 2.HAL 160-173

9. Cecep Triwibowo, Sulhah Yuliawati \& Nur Amri Husna.2016. HANDOVER SEBAGAI UPAYA PENINGKATAN KESELAMATAN PASIEN (PATIENT SAFETY) DI RUMAH SAKIT. Jurnal Keperawatan Soedirman (The Soedirman Journal of Nursing), Volume 11, No.2 HAL 7680

10. Hakim, L. Pudjirahardjo. W. 2014. Optimalisasi Proses Koordinasi Program Keselamatan Pasien (Patient Safety) Di Rumah Sakit X Surabaya. Jurnal Administrasi Kesehatan Indonesia. Vol. 2, No. 3. Hal 198-208

11. Keles, W, H., Kandou, G, D., Tilaar, Ch, R., 2015. Analisis Pelaksanaan Standar Sasaran Keselamatan Pasien di Unit Gawat Darurat RSUD Dr. Sam Ratulangi Tondano Sesuai Dengan Akreditasi Rumah Sakit Versi 2012. Jurnal FKM Universitas Sam Ratulangi Manado. JIKMU. Vol. 5, No. 2. Hal 250-259 
